\title{
SOMATIZAÇÃO EM MIGRANTES DE BAIXA RENDA NO BRASIL
}

\author{
Miguel Antônio de Mello Silva \\ Faculdades Integradas do IPEP/Campinas
}

Marcos de Souza Queiroz

UNICAMP

\begin{abstract}
RESUMO: Este artigo tem por objetivo compreender o entrelaçamento da cultura com reações psicológicas de indivíduos expostos ao processo de migração e estabelecer relações entre o fenômeno da migração e adoecimento psicossomático. O enfoque metodológico é essencialmente qualitativo, baseado em representações sociais de pacientes migrantes e da equipe de funcionários e profissionais de um centro de saúde do município próximo de Campinas. A análise demonstrou que a migração era percebida negativamente, como uma causadora de doenças quando havia perda do emprego/renda e fragmentação de laços familiares e comunitários. Se tais elementos estavam estabilizados, fatores estressantes do cotidiano permaneciam mascarados (mantidos fora da consciência) e a piora da saúde não era atribuída à migração ou à qualidade de vida. $\mathrm{O}$ problema da migração e doença, pela perspectiva do centro de saúde, incluía abordagem terapêtica exclusivamente biológica sem outra perspectiva que contribuísse para os sujeitos assimilarem as novas condições de vida num novo ambiente sócio-cultural.
\end{abstract}

PALAVRAS-CHAVE: Psicologia Social; psicossomática; migração; psicanálise; medicina social.

\section{SOMATIZATION IN BRAZIL'S LOW-INCOME MIGRANTS}

ABSTRACT: This paper aims to debate relations between culture and psychological reactions of individuals exposed to the process of migration and to establish relations between migration and psychosomatic sickening. The methodological approach is essentially qualitative and based on social representations of migrant patients, staff and professionals of a public health unit near Campinas. The analysis demonstrated that migration was negatively experienced as producing ailments when loss of job/income, break of family/community ties was involved. When these elements were stabilized, stressful factors of daily life remained covered (out of conscience) and worsening in health condition was attributed neither to migration nor to life quality. The problem of migration and ailments, from the health center perspective, involved merely biological procedures and did not include additional perspectives to help patients to assimilate their new life conditions in a new social environment.

KEYWORDS: Social Psychology; psychosomatics; migration; psychoanalysis; social medicine.

Este artigo tem por objetivo compreender, num sentido mais abrangente, o entrelaçamento da cultura com reações psicológicas de indivíduos expostos ao processo de migração. Pretende-se, num sentido mais estrito, estabelecer a relação entre a migração e a doença a partir de representações sociais feitas por pacientes migrantes de Campinas. A abordagem teórica mais ampla que dá suporte a esta proposta é essencialmente interdisciplinar, envolvendo áreas da Psicologia Social, Psicanálise e Antropologia Social e Cultural.

As Ciências Sociais constatam que a conexão entre o adoecimento e o ambiente não é meramente biológica, mas necessariamente inclui uma dimensão sociocultural (Griffith, 1992). As mudanças aceleradas proporcionadas pela modernidade produzem, juntamente com o desenvolvimento tecnológico, re-acomodações traumáticas em razão de alterações nos laços sociais e na relação com o meio-ambiente que são, em grande parte, produtoras de estresse e de problemas de saúde (Gold, 1992; Ory, 1991; Quintero, 1989; Smith, 1996; Sullivan, 1993).
O conceito antropológico de eficácia simbólica (LeviStrauss, 1996) e do efeito placebo na Farmacologia (Schonauer, 1994) aliam-se aos da Psicanálise (Volich, 2000), demonstrando que entre a saúde e a doença reside uma vida fantasmática corpórea em que psiquismo e organismo se influenciam a partir de relações construídas social e psicologicamente.

Os estudos qualitativos da migração interna brasileira e do choque dos modelos de vida rural e urbano (Caldeira, 1984; Durham, 1978) pouco têm discutido sobre os desdobramentos na saúde. Contudo, várias pesquisas têm apontado para a necessidade de criação de recursos terapêuticos que incluam uma dimensão sociocultural (Corin, 1990; Fabrega, 1989; Grypma, 1993). Nesse sentido, o nosso estudo é pioneiro.

A pesquisa iniciada em março de 2000 envolve trabalhadores migrantes adultos, de renda e escolaridade baixas e que se deslocaram para a região de Campinas, SP. Esta população provém de regiões menos desenvolvidas como o Nordeste e o norte de Minas Gerais. 


\section{Método}

O método de pesquisa utilizado foi o de vértice qualitativo. $\mathrm{O}$ campo da pesquisa foi um centro multidisciplinar de saúde básica do SUS, na cidade de Hortolândia (subúrbio metropolitano de Campinas-SP).

A aproximação com o conteúdo das falas dos indivíduos entrevistados foi realizada a partir da perspectiva das representações sociais. Sob tal perspectiva, considera-se que as entrevistas contenham um tipo de saber socialmente negociado, contido no senso comum e na dimensão cotidiana, que permite ao indivíduo uma visão de mundo que contém, em menor escala, todos os ingredientes do pensamento e da vida social e capacita o indivíduo a orientar seus projetos de ação e as estratégias que desenvolve em seu meio social (Moscovici, 2003).

Foram selecionados 19 participantes em dois grupos. O primeiro grupo tinha 11 pacientes adultos da clínica médica, com idades entre 22 e 65 anos, sem história psiquiátrica, escolaridade e renda baixas (de 0 a 104 dólares/ mês). Migrados de 22 dias a 3 anos de áreas de menor desenvolvimento em busca de trabalho, os problemas de saúde mais comuns deles eram hipertensão arterial, reumatismo e diabetes. O segundo grupo tinha 8 funcionários das áreas de: coordenação (1), clínica geral (2), enfermagem (1), nutrição (1), assistência social (1) e psicologia (1). O nível educacional deste pessoal era superior e as rendas variavam de 600 a 1000 dólares/mês, com exceção da recepcionista, que tinha nível escolar médio e renda de 250 dólares/mês.

A amostragem foi deliberada (Bogdan \& Biklen, 1998b; Pope \& Mays, 1995) porque se escolheram sujeitos cujas características favoreciam a obtenção de informações substanciais para aprofundamento na problemática (Jaspers, 1979; Martins \& Bicudo, 1989; Minayo, 1996). O tamanho de amostra foi definido pelo método de saturação (Bogdan \& Biklen 1998a; Kvale, 1996; Morse, 1994).

A coleta de dados utilizou duas técnicas ou instrumentos: a) Observação participante, realizada por dois anos de permanência do pesquisador em campo, participando das atividades do centro (rotinas, reuniões administrativas, comemorações, grupos terapêuticos, etc.) e visitando a região atendida com um guia local também migrante. b) Entrevistas semi-estruturadas de perguntas abertas, técnica apropriada porque, ao contrário de entrevistas estruturadas com pré-categorização de respostas, possibilita respostas inesperadas e descritivas de opiniões e sentimentos (Fowler, 1993).

Uma fase piloto para teste do roteiro de perguntas precedeu as entrevistas que, em geral, foram gravadas em dois encontros. Os pacientes foram entrevistados no mesmo dia da consulta médica e o foco estava em suas opiniões sobre a migração, o adoecimento e as condições de vida (atuais e prévias). As entrevistas com membros da equipe e funcionários focalizaram opiniões que tinham sobre a problemática dos migrantes e nos serviços que ofereciam no centro. Aos grupos foi assegurado o anonimato.

As falas foram transcritas e editadas com o intuito de facilitar a leitura e preservar o significado; alguns ajustes foram feitos (Blauner, 1987; Jakobson, 1969): reorganização e supressão coerentes das contribuições do entrevistador, dos espaçadores conversacionais, dos falsos começos e da linguagem fática.

A análise dos dados foi feita convertendo os dados coletados em categorias e unidades de significados, levando-se em conta a frequiência, a relevância e também a interpretação que os atores davam aos temas de pesquisa. Cada uma das entrevistas recebeu um relatório específico, realizado no mesmo dia, que incluía elementos implícitos não detectáveis pela transcrição, tais como silêncios significativos, ironias presentes no tom de voz, contradições e ambigüidades significativas, etc. (André, 1983; Ludke \& André, 1986; Trinca, 1984).

A aproximação teórica mais ampla utilizada pela pesquisa refere-se à Teoria da Ação Comunicativa de Habermas (1985), por se tratar de uma perspectiva bastante abrangente e multidisciplinar, que consideramos apropriada para dar conta da complexidade do objeto de pesquisa proposto.

A perspectiva habermasiana realiza a síntese do funcional-estruturalismo, do interacionismo simbólico e do materialismo histórico, ao considerar a reprodução cultural como dependente não só das interpretações simbólicas, mas também de processos objetivos de integração e socialização (individuação), em cujo centro estaria o processo comunicativo, que se manifesta através de fases evolutivas. Em tal contexto, a realidade individual e coletiva (dimensões subjetiva e objetiva), o ideal e o empírico, acomodamse em dois níveis fundamentais: 1) mundo-da-vida - terreno que envolve os níveis cultural, social e individual, com padrões interpretativos transmitidos culturalmente em processos de interpretação compartilhados; 2) sistema: plano abstrato representado pelos níveis político, econômico e administrativo, em que os indivíduos agem sem qualquer necessidade de justificação normativa para seus comportamentos.

A interação entre o mundo da vida e o sistema permite o desenvolvimento de certos padrões comunicativos que, em semelhança com o processo de desenvolvimento cognitivo humano de Piaget, revela um plano ideal (utópico) e real, no qual a diferença poderia conter patologias e distorções comunicativas. Tais condições afetam diretamente o comportamento do indivíduo, inclusive na situação de sua saúde.

\section{Resultados e Discussão}

No Brasil, os grandes centros atraem trabalhadores pobres que renunciam a vida rural ou semi-rural para mi- 
grarem por razões de trabalho: busca de emprego, aposentadoria, mulheres que se separaram dos maridos e buscam trabalho para custeio doméstico, etc.

Áreas pouco valorizadas no entorno metropolitano e de pouca infra-estrutura urbana (ruas não-pavimentadas e falta de rede de esgoto) são locais de escolha para a maioria destas pessoas por causa da proximidade de empregos na grande cidade e pelo baixo custo dos terrenos. Nesses lugares, a presença do Estado é fraca e existe acentuada instabilidade social com elevados índices de criminalidade.

Os migrantes realizam a mudança em grupo e fazem uso de redes sociais, envolvendo principalmente parentes já migrados. Nesse contexto, a oferta que recebem para se acomodar provisoriamente na casa deles é fundamental. Passam, com isso, a viver em condições péssimas, ladeados de criminosos, incertos quanto a encontrarem emprego e precariamente apoiados pelos parentes.

A baixa renda não lhes confere autonomia tendo que conviver em família extensa que, por um lado lhes possibilita uma adaptação gradual à nova vida, por outro limita a consolidação da identidade individual própria da modernidade. O convívio comunitário é restrito ou quase inexistente, o que os deixa muito ligados à família.

O apego aos parentes é importante porque o grupo de parentes também funciona como unidade de renda. Nessa configuração, a identidade automaticamente convocada é a de trabalhador e o tema do trabalho funciona como mediador das relações de parentesco, fato este presente em todos os nossos depoimentos. É em torno do trabalho que a família e a vida social se organizam; é por meio dele que se determinam os papéis domésticos de homens (que saem para trabalhar) e de mulheres (que permanecem em casa envolvidas com as tarefas domésticas e o cuidado de crianças), distantes do mercado e da qualificação (Zaluar, 1994).

\section{A Partida}

A sobrevivência material e a segurança psíquica encontram no emprego as possibilidades de efetivação, porque ele determina a permanência ou não do migrante no novo local. A sobrevivência é garantida pela composição de renda de diversas pessoas da família e isto implica que a migração deve ocorrer em grupo. As falas seguintes trazem a motivação para migrar.

Trabalhava lá só pra comer. Minhas irmãs estavam aqui e viemos. Todos arrumaram emprego e a gente está melhor porque trabalha, né? (mulher, 56 anos)

$\mathrm{O}$ serviço lá foi ficando fraco e depois fracassou. Eu vim primeiro morar com meu irmão e depois trouxe a família. (homem, 40 anos)

A busca de melhores condições materiais de vida é fator básico para a migração, mas não único, visto que ela também poder ser motivada por razões psicológicas como a de, por exemplo, evitar o prolongamento de uma situação emocionalmente insustentável.

Não gostava de lá: ficava nervosa, a pressão subia. Gosto daqui e depois que vim, os filhos já trabalhavam, então melhorei. (mulher, 48 anos)

Minhas amigas de lá eram fofoqueiras. Se eu faço algo, logo todo mundo está sabendo. Aqui não: cada um cuida da sua vida. (mulher, 21 anos)

\section{Os Atrativos}

$\mathrm{O}$ grande centro atrai pessoas de comunidades rurais fechadas e simbolicamente saturadas também por causa de outras vantagens que são próprias da vida moderna. Uma delas é a possibilidade de ter acesso à saúde, empreender o controle de natalidade, acessarem programas de planejamento familiar e meios contraceptivos que liberam a mulher do papel fixo de criar filhos. Com isso, o grande centro viabiliza o acesso a uma identidade em que o corpo e o sexo figuram como meio de prazer (e não de mera reprodução), conferindo-lhes liberdade que não podia ser experimentada em uma sociedade de organização simples, que determina papéis em função de interesses coletivos. As mulheres podem, agora, por exemplo, deixar os filhos em creches para empreenderem pequenas atividades remuneradas, como a de revenda de produtos cosméticos ou de faxina (que dá ganho considerável); ou simplesmente podem ter mais tempo para si próprias: "De tarde os filhos estão ou na escola ou na creche e posso fazer um biquinho. Lá não tem médico igual aqui. Comecei a vir em ginecologista quando vim morar aqui” (mulher, 32 anos).

O conhecimento (não a força física) é o principal produto de troca na obtenção de melhores colocações e as pessoas podem ter um acesso mais facilitado a ele nas escolas, adquirindo uma visão menos paroquial de mundo e maior liberdade social.

Eu sempre trabalhei na roça e não quero isso pra minha filha. Pus ela no curso técnico de enfermagem porque sem estudo aqui não vai pra frente. (mulher, 48 anos)

Tem que pensar alto: fiz técnico e consegui esse emprego na prefeitura. (homem, 30 anos)

Os que conseguem conquistar um lugar nesse novo ambiente ganham a libertação de um mundo fechado. Agora, por exemplo, eles podem viajar, conhecer lugares diferentes, porque têm renda. Os bem-sucedidos viajam com dinheiro e, muitas vezes, de carro próprio, para a localidade de origem, reatando relacionamentos afetivos e memórias pessoais.

Ser capaz de fazer isso representa uma forma de demonstração de sucesso e triunfo. Então, segundo a óptica dos conterrâneos, ressurge como herói e isto lhes eleva a autoestima, reforça as motivações iniciais de mudança de ci- 
dade, melhora o desempenho social e fortalece o equilíbrio psicossomático: "Lá só volto pra visitar (ri) uma ou duas vezes por ano. Eles acham que a gente virou bacana se chega de carro lá. Não têm idéia de como foi difícil conseguir o que eu tenho..." (homem, 34 anos).

\section{As Contradições}

A conquista do novo status social não ocorre sem renúncias, perdas e contradições. Mudar de cidade implica riscos e não há garantias a priori. Quando as aspirações que motivaram a mudança são alcançadas, a nova situação é percebida positivamente. Mas, do contrário, se existem perdas, fracassos decorrentes da mudança, o novo contexto e a nova situação são vistos como sombrios e pouco atrativos.

No segundo caso (negativo) os sujeitos se sentem desenraizados, inseguros e incapazes de lidar com o cotidiano; a auto-estima cai, surgem depressão, isolamento e sensação de fragmentação-elementos que precedem os desequilíbrios psicossomáticos.

A individualidade, que funcionaria como uma vantagem para os vitoriosos, acentua ainda mais a sensação de desamparo porque, em um contexto moderno, é comum o esfacelamento das relações comunitárias. Sem apoio, a confiança no ambiente diminui, gerando instabilidades emocionais e sintomas psicossomáticos.

Tem os amigos e os vizinhos, mas cada um cuida da sua vida. A gente se sente muito abandonada aqui. Dá uma "gastura", um nervoso, uma vontade de chorar.. fico louca, tenho vontade de subir no muro, gritar, fazer uma loucura... estou presa, sozinha aqui. (mulher, 32 anos)

Em decorrência da modernidade, na expressão de Habermas (1985), a vida é colonizada e regulada por um sistema impessoal, no qual as pessoas facilmente perdem o sentido de existência para desempenhar papéis que guardam pouca ou nenhuma relação com suas aspirações pessoais. A distância com o âmbito do sistema, que regula a vida social e econômica, produz distorção comunicativa e alienação, condições que acabam levando à doença.

A gente é pobre e tem que se submeter porque precisa do emprego... Não posso largar dele porque quem vai criar os meus filhos? (mulher, 39 anos)

Sou velha, uma laranja chupada. Antes de morrer, o "véio" ficou pra lá e pra cá dando trabalho pros filhos. Tenho que dar lugar pros mais jovens que têm que trabalhar e a vida deles pra viver.. mas queria mesmo era casar com um velho rico (ri). (viúva aposentada)

Nesse contexto, as relações sociais básicas de família e de vizinhança estão submetidas a uma ordem impessoal, segundo a qual as pessoas são peças de uma engrenagem maior, à qual devem se ajustar para depois serem descar- tadas. Ocorreria, então, a perda de sentido de uma participação efetiva no processo de vida, criando vácuo existencial e alienação social. Há um esvaziamento da sensação de pertencimento comunitário e a ordem (leis e normas) não é vista mais como uma conquista a ser mantida por ações sociais efetivas e asseguráveis. Nesse vácuo, a contravenção e a criminalidade se alastram e as pessoas de bem se sentem vulneráveis: "Em casa ninguém freqüenta nem bar, nem baile. Esses lugares a gente sabe que tem gente que não presta... até sabe quem, mas faz de conta que não sabe" (mulher, 34 anos).

O efeito colateral do processo de urbanização e de modernidade é percebido no empobrecimento dos valores da vida normativa e do ato social, gerando adoecimento comunitário (Habermas, 1985). No plano individual, isto se manifesta na forma de estresse, saudade e depressão, subprodutos da angústia de aniquilamento, que nasce da desesperança e se reflete no esgotamento do que Habermas denominara de energias utópicas.

\begin{abstract}
A gente vive melhor mas não pode contar com ninguém. Vizinho aqui não é igual ao que era lá. Lá eu conhecia todo mundo e era amiga de todos. Lá tinha praça e todo mundo saía de noite. Aqui também tem, mas não é bom ir, não. Tenho saudade disso. (homem, 49 anos)
\end{abstract}

Em geral, o equilíbrio psicossomático do migrante mantém-se pelo equilíbrio entre as compensações e as renúncias feitas, a aculturação ao novo contexto, a adoção da nova identidade.

\section{Contradições Familiares: Refúgio e Acusação}

Não menos importante é a capacidade de articular dois universos de valores distintos: o da vida rural e o do mundo moderno. Os valores do primeiro estão pautados pelo que Durkheim chamava de solidariedade mecânica das relações sociais, baseado na identidade comunitária, em tipo de conhecimento paroquial e na segurança dos laços consanguiíneos. No segundo, a pauta é o da identidade individual, impessoal e mutante, no conhecimento especializado relativista e nas relações de interesse (Moore, 1968).

A importância de enfatizarmos a existência desses dois universos se explica pelo fato dos sujeitos fazerem uso de ambas as referências para conduzir suas ações. Por exemplo, vários deles valorizam a família como lugar de refúgio e segurança, mas dentro delas também há acusações e tensões.

Se a pessoa fica longe da família, pode causar até doença... É melhor a gente ficar com a família, em casa... sabemos quem é quem e assim não compromete. Vivo em paz com os parentes porque fora da família não tem com quem contar. É sangue da gente e então tem que ajudar se precisar. (homem, 49 anos)

A ideologia da excelência familiar e comunitária não significa a inexistência de tensões, acusações e crises nes- 
se contexto. Em face do apelo que a modernidade exerce no indivíduo, no sentido do que Habermas denomina de processo de individuação, as tensões e crises são quase sempre relativas à efetivação de projetos individuais, quando estes não recebem a oposição da família. Tal tipo de tensão é principalmente experimentado pelos mais jovens que, em virtude da força da adolescência, os leva à negação dos valores conservadores. Por terem absorvido melhor as referências simbólicas da individualidade do novo contexto, os adolescentes ficam, social e psicologicamente, acuados entre os valores modernos e os tradicionais. Embora possam desenvolver uma atitude de rompimento com estes últimos, a necessidade de apoio familiar os contém.

Falam que ele encheu minha cabeça pra ser modelo e não me deixam mais namorar com ele. A inveja dos parentes é terrível. Querem que a gente se dê bem, mas quando se conquista algo querem também pra eles ou põem olho-gordo (mulher, 24 anos).

Meu marido confiou na minha cunhada e perdeu tudo! A gente não tem para onde ir (chora). Pensávamos que dava para confiar em parente. Estou deprimida e desesperada.

O desejo de emancipação familiar e a dependência determinam dissonâncias cognitivas e descontinuidades culturais. Ainda que as pessoas estejam tentando se ajustar a um contexto mais individual, elas se mantêm organizadas coletivamente e servem como justificativa para as regras de relacionamento entre pais e filhos, por exemplo. É como se estivessem em um contexto moderno individualista, mas se conduzindo por padrões rurais, que priorizam a manutenção do grupo. Esta forma de controle social, que afeta significativamente os jovens, se expressa através de acusações de serem os parentes "caipiras", até a ruptura com a família a partir do momento que conseguem obter renda.

Pegam no pé com tudo. Queria que eles entendessem, mas não entendem que aqui é assim. Fui rejeitada porque não nos casamos na igreja. Falam que mulher direita não faz isso. Isso me magoa muito... Não me aceitam... mas pago minhas contas. Não fico rastejando e sabem onde moro (mulher, 24 anos).

Especialmente para os mais jovens, perder a aceitação dos parentes ou ter os planos individuais impedidos gera instabilidades emocionais e farta munição para discussões recorrentes. Na realidade, parece que as partes não se entendem porque há uma distorção comunicativa por se usarem pautas de sistemas de valores distintos e de estratégias que geram estranhamento mútuo, aborrecimentos e problemas psicológicos.

\section{O Definitivo e o Provisório}

É dentro das descontinuidades de jogos de força complexos que o sujeito consegue avaliar sua experiência migratória e o seu novo modo de vida, tentando entender se valeu ou não a pena migrar e se a mudança será definitiva ou provisória. Neste balanço, por exemplo, uma pessoa que faz uma avaliação positiva da mudança pode dizer:

Falar que a gente tem dinheiro é mentira. A gente mora longe, em casa simples, mas tem escola, posto e creche. Demorou pro meu marido arrumar emprego. Ficamos quatro meses "de favor" na casa da minha cunhada. Pensamos até em voltar. Mas depois que ele conseguiu emprego, ficamos.

Entre nossos entrevistados, constatamos que a esperança está apoiada fundamentalmente no fato de se ter ou não emprego, família e marido (para as mulheres). Usufruir alguns desses elementos, ter expectativas de continuidade - ao contrário da desesperança da descontinuidade que levariam a novos esforços para retornar ao local de origem carregando uma sensação de fracasso - eram peças fundamentais para o controle do estresse da vida cotidiana e fortalecia o poder de enfrentamento das dificuldades inerentes à vida da classe trabalhadora pobre.

Quando tais condições eram preenchidas, os elementos desfavoráveis da vida diária surgiam apenas de maneira esparsa nos depoimentos, como que encapsulados, cindidos e eram acompanhados de justificativas que os qualificavam como sendo eles de fácil superação. Era bem freqüente um discurso do triunfo, que negava as contradições da nova vida. No que diz respeito à saúde, tais discursos expressavam o fato de que, embora houvesse complicações funcionais como obesidade, diabetes e hipertensão arterial, elas eram pouco consideradas: "A gente é forte e tem saúde... são só umas coisinhas que não atrapalham nada".

Tais pacientes, principalmente homens, são alvo de preocupação justamente porque ficam alheios à condição física pessoal até que comecem a surgir prejuízos importantes do desempenho de trabalho. Levando-se em conta o fato de serem trabalhadores braçais, caso adoeçam, deixarão de trabalhar sem encontrar meios substitutos de renda. Isto se deve ao fato de que, nessa organização social, a qualificação do trabalhador se constitui em um valor de mercado. Assim, por tensão emocional e conflitos interpessoais decorrentes da incapacidade do exercício do papel social de trabalhador forte, tão valorizado pela família, e sem a mesma liberdade de expressão de queixas de fragilidade física, os homens eventualmente serão pegos num círculo-do-mal que os empurra cada vez mais em direção a doenças graves de evolução silenciosa (Boltanski, 1979; Dejours, 1992; Queiroz, 1991).

Fiquei impotente e prejudicava a relação com a minha mulher até que tive que parar de trabalhar. A família dizia que eu não trabalhava mais por "frescura" pra não pegar no batente. Fiquei muito deprimido e quase separamos. Quem ajudou foi a psicóloga (homem, 32 anos) 
Sem qualificação, a importância do vigor físico é um notório divisor de águas porque sem ele é impossível o sustento. Sujeitos que atravessaram o período de trabalho e chegaram à aposentadoria se depararam com constatações frustrantes que denotam ser a dimensão social do sistema, além de impessoal, também defeituosa: "Trabalhei a vida toda para ter uma casinha que vendi para vir para cá ficar perto das minhas irmãs. Mas com a aposentadoria não consigo comprar outra, não posso trabalhar e estou vivendo de favor" (homem, 65 anos).

O efeito psicológico dos que avaliam a migração $n e-$ gativamente é uma desesperança geral. São pessoas sem ganhos ou meios de sobrevivência, que experimentaram desestruturação familiar. Podemos afirmar que há duas instâncias de enfrentamento da nova realidade: o emprego e a família.

No emprego reside a principal conexão dos nossos entrevistados com o nível do sistema social mais abrangente. Por outro lado, para as famílias trabalhadoras, a família é o principal meio de reconhecimento e de reasseguramento dos projetos de vida. A sua participação no equilíbrio psicossomático dos sujeitos é fundamental, porém, não decisiva, visto que o projeto familiar fica comprometido na ausência de emprego/renda, o seu principal elemento viabilizador.

Por ambos os vértices de análise, é possível compreender do que Habermas se refere como colonização do mundoda-vida pelo sistema. No nosso caso, constatamos que o funcionamento das relações familiares é justificado segundo valores do sistema, tendo a renda como um fator proponderante, criando toda sorte de distorções comunicativas intra-pessoais e inter-relacionais. Enfim, as relações entre estes elementos (emprego/renda e família) são complexas e não podem ser dimensionados a não ser por uma perspectiva interdisciplinar, que inclua o nível sociocultural, econômico e psicológico.

Se há emprego/sustento, mas uma má convivência familiar, há a alternativa de transformação pelo rompimento e início de uma vida mais independente. A fim de realizar uma ruptura com os padrões e compor um novo lugar social que seja mais afinado com um modo de vida individual, menos paroquial e socialmente mais inserido no mundo moderno, ser homem constitui uma vantagem.

Os homens têm maior liberdade para realizar mudanças, porque estão desobrigados da criação de filhos e puderam desenvolver algumas habilidades valorizadas pelo mercado de trabalho. As mulheres, por sua vez, além de se sentirem obrigadas a criar filhos, permaneceram boa parte da vida exercendo a função de donas-de-casa, sem desenvolver qualificações profissionais. Portanto, os nossos dados revelam uma profusão de casos nos quais mulheres infelizes e doentes permaneciam atadas a um casamento apenas porque oferecia sustento, que possibilitava concluir a criação dos filhos: "A gente tem que se conformar, né? Não dá pra dizer que sou feliz [no casamento] mas tenho filhos pra criar".

Outros casos revelam situações nas quais o rompimento matrimonial obrigou a mulher a migrar para um meio urbano mais desenvolvido e a procurar emprego, rompendo com sua rede social e promovendo um desequilíbrio psicossomático: "Fui largada e mudei só por causa de dinheiro. Mas ficava muito nervosa e minha pressão subia. Ia ao médico sempre e me intoxicava de remédio. Era dor demais!".

\section{Compreendendo os Efeitos da Migração}

A partir da escuta de experiências, buscamos construir uma proposta que explicitasse as apreciações que os sujeitos fazem da migração, as formas de efetivação dos ajustamentos e a repercussão disto sobre o quadro de saúde deles.

Se há boa convivência familiar, mas não há emprego/ sustento, mantém-se um modelo de solidariedade mecânica inquestionável razoavelmente equilibrado. Todavia, existem diferentes expectativas entre homens e mulheres. Por exemplo, em situações de ausência ou de grande diminuição da renda, dos homens é cobrada a retomada do sustento familiar e, caso isso não ocorra, diante da expectativa cultural de serem provedores do lar, o equilíbrio familiar fica tenso a ponto de, inclusive, romper-se: "Como podia continuar com ele se ele não punha um grão de arroz em casa? Agüentei 12 anos as suas bebedeiras, mas um dia eu fugi de noite pra morar com a minha irmã que trabalhava e tinha cabeça diferente".

Se falta renda na vida destas pessoas, os relacionamentos românticos enfraquecem e o cuidado materno modifica-se: "Não criei filho pra ser vagabundo. A menina tem que cuidar da casa, mas ele não. Peguei um pedaço de pau e falei pra arranjar um emprego. Não estou negando moradia mas tem que ajudar também, né?".

Sentimentos ternos existem, só que eles são condicionados pela necessidade imperativa das pessoas de sexo masculino preencherem o papel de provedor familiar. Nesse sentido, a valorizada imagem de trabalhador se diferencia radicalmente da imagem do vagabundo, encostado e malandro, própria dos indivíduos de sexo masculino que deixam de preencher o papel de provedor.

Se não há boa convivência familiar e nem emprego/ sustento, a sensação de insegurança, associada à nova vida, acentua-se e as razões de continuar ali são questionadas. É nesta situação que as queixas de saúde aparecem:

Vim para cá com ele. Tivemos esta filha maravilhosa, mas depois que ele foi embora, não tem mais sentido ficar aqui: não conheço ninguém e se não fosse meu irmão mandar dinheiro, ia morrer de fome.

Se a pessoa não está feliz num lugar, ela fica doente. Esse é o meu caso. Toda manhã eu abro o olho e penso: o que eu estou fazendo aqui? 
Estas pessoas trazem descrições subjetivas de angústia (de aniquilamento) contra o qual formaram um sistema psicológico defensivo, que rechaça quase tudo que vem do meio circundante, sentido como ameaçador e insatisfatório. A comunidade, o sistema de saúde, o bairro e a família constituem os alvos prediletos de queixas e reclamações.

Na minha cidade, as pessoas levavam cadeira para sentar na calçada de tarde para conversar. Aqui não tem nada disso. O bairro é perigoso, não tem onde passear. Piorei muito depois que vim para cá. Tudo por causa do nervoso.

Família... o que é família? Pois não te disse que foi parente que passou a perna no meu marido? Antes eu acreditava em parente. Hoje, não caio mais nisso, não. Quando você menos espera, é o parente que vai te apunhalar pelas costas.

A ampla categoria do "nervoso" é, muitas vezes, recuperada pelos sujeitos para explicar como reagem às contrariedades da vida. Não que tais contrariedades, enquanto imponderáveis da vida, não estejam presentes na vida das pessoas satisfeitas com a migração. O que ocorre nessa situação é um interessante fenômeno de contraste perceptivo pelo qual estes elementos ficam mascarados pelo fato de se ter emprego. Como já dissemos, estar empregado significa ter renda, o que assegura ao sujeito segurança, sobrevivência e realização de aspirações. Obviamente, se isto incluir o apoio de parentes, a segurança será ainda mais efetiva e outros desconfortos tornam-se, automaticamente, secundários ou irrelevantes, permanecendo "isolados" do campo da consciência. Quando, por outro lado, falta emprego e apoio familiar, a situação será experimentada como uma ruptura traumática, que desencadeia um movimento regressivo pelo qual se busca retornar ao momento que antecedeu a mudança, isto é, resgatar o sentido original de suas vidas: "Deixei tudo lá pra vir pra cá e sofrer pra quê? Pra ficar doente de nervoso aqui?’.

Para este grupo, os problemas de saúde são identificados como resultados de uma mudança que não deu certo. Em razão disso, este grupo de sujeitos associou a migração com adoecimento e trouxe queixas de depressão, medos, insônia, sensação de perda de identidade, medo de colapso psíquico, dores físicas, problemas de visão, dores vagas no coração, complicações sistêmicas e muita saudade: "Como que vou voltar se vendi tudo o que tinha lá?".

A resistência contra retornar ao local de origem resulta tanto de fatores materiais como de fatores psicológicos. Voltar significa ceder à sensação de derrota, fiasco e correr o risco de se sentir publicamente embaraçado, pois as expectativas para a partida não previam desfechos fatídicos. Assim, o retorno normalmente só ocorre depois de todas as possibilidades de permanência já terem sido tentadas sem sucesso algum e de muito desse tempo ter sido preenchido com sensações crescentes de impotência, sentimentos de saudade e de inadequação que geram desequilíbrio psicossomático. Assim, não é incomum o adoecimento físico preceder o retorno ao local de origem: "Já faz duas semanas que rolo na cama e não durmo. Só fico pensando na vida e tentando um jeito de voltar".

A magnitude dos problemas correntes da nova vida será sentida de acordo com a capacidade de enfrentamento que a pessoa percebe em si. Evidentemente, uma situação de baixa estima reduz a capacidade de adaptação às novas condições e aumenta a probabilidade de somatizações. $\mathrm{O}$ trecho de entrevista abaixo é um caso em questão.

Sou fraca e desde pequena fui doente... minha mãe disse que era pra eu morrer. Depois, as internações, as zonzeiras, os pedaços de sangue na vista, problema no "miolo"... Preciso do meu irmão, mas ele está desempregado e quer que eu saia da casa dele. Acho que já deu pra perceber.. não acha que tenho um problema no cérebro que ainda não descobriram?

Em resumo, a partir desse modelo proposto, a migração é apenas mais um desafio da vida. Ser capaz de superar desafios e efetuar conquistas é poder experimentar a sensação de ter criado algo pessoal e sair da experiência fortalecido.

Voltei pra lá pior do que cheguei aqui. Não conseguia mais viver lá porque era como se eu tivesse que voltar e lutar. Agora que lutei e tenho minha casa e a minha família, ando de cabeça erguida. A gente aprende com a vida, né?

Da dinâmica da migração, participa uma constelação de aspectos da vida cotidiana: emprego, família, bairro, vizinhança, etc. dentro de uma ambientação que deve sustentar a esperança da continuidade do projeto de vida, segundo as escalas de valores de uma cultura cheia de contradições.

Poder migrar voluntariamente tentando evitar a fragmentação da perda de identidade representaria poder contemplar-se com vida e esperança para avançar por um cotidiano contraditório e difícil, mas reconhecível como uma criação pessoal. Logo, a migração não é uma categoria que encerra um sentido em si mesmo, um fenômeno isolado, mas, ao contrário, é poder (ou não) desconstruir e reconstruir modos de vida avaliados como compensadores por serem eles uma extensão criativa das pessoas.

\section{Considerações Finais}

Os nossos dados referem-se a uma população de migrantes, provenientes de contextos rurais ou semi-rurais de outros estados brasileiros, principalmente o nordeste. Em todos os casos estudados, a vinda para São Paulo significou a busca por emprego e por melhores condições de vida. Em todos os casos, o processo de migração contou com a colaboração de parentes, que já estavam estabele- 
cidos no local de destino. Tal colaboração significa desde indicar possibilidades de emprego e de moradia, até dar abrigo e sustento até que o migrante encontre condições adequadas.

Em nossa amostra, o padrão mais recorrente de migração é representado pelo indivíduo de sexo masculino que planeja a migração a partir de contatos com parentes já estabelecidos no local de destino. Tal planejamento inclui uma provisão financeira para dar conta dos primeiros meses no novo local. Quando o migrante é casado, o cônjuge e os filhos só migraram após ter encontrado emprego.

Temas relativos à proteção e segurança urbana e o convívio com marginais foram mencionados recorrentemente como um fator que gera estresse. $\mathrm{O}$ ambiente perigoso da periferia urbana de Campinas foi também lembrado consistentemente. Neste contexto, é importante lembrar a falta de ambientes que possibilitariam uma convivência social, como uma praça pública, na qual os membros da comunidade possam exercer o direito a um convívio humano descontraído. O único local que serve a este propósito é o bar, mas ele não é exatamente um ambiente adequado para o trânsito da família. O local de habitação de todos os nossos entrevistados foi considerado árido e gerador de estresse pela totalidade de nossos entrevistados.

As relações com a vizinhança não podem ser caracterizadas como propriamente solidária. Fora do âmbito familiar e de conterrâneos, o meio social é percebido com uma tendência negativa. Qualquer outro tipo mais amplo de inserção social ou de sentimento de pertencimento, como aquele proporcionado por clubes, praticamente não existe.

Nas relações sociais, a solidariedade mecânica familiar, típica do mundo rural, opunha-se às relações individuais da modernidade, gerando contradições e descontinuidade referencial no trabalho e na família. A consciência dessa oposição como um fator estressante e capaz de afetar tanto a saúde como a qualidade de vida variava com a sensação de segurança provenientes do emprego e do apoio familiar. Isto é, quando sentiam segurança nesses quesitos, os elementos estressantes eram menos percebidos e o valor dado à migração era mais positivo. Por outro lado, quando havia insegurança no âmbito do emprego ou da família, tais elementos eram percebidos negativamente e o valor dado à migração era negativo.

A grande maioria afirmou ser a migração positiva e acreditava ser ela incapaz de causar doenças. Por outro lado, dois participantes, que afirmaram a migração ter sido negativa, atribuíam a ela poder de causar perturbações de saúde e trouxeram vários aspectos do novo ambiente que eles consideravam como produtores de estresse.

Para os homens, provedores da família, estar doente significava incapacidade de trabalhar fisicamente e perder seu espaço de reconhecimento, o que os conduzia a maiores perturbações psicossomáticas. O processo de adoecer apresentava-se como condição de fracasso intolerável, uma vez que tinham vendido tudo e deixado suas comunidades originais para terem que voltar em condição ainda mais precária do que quando partiram. Ao mesmo tempo, viver sem ter controle sobre o destino pessoal, sem emprego, lazer ou vida social no interior de uma favela da periferia representa um quadro distante do idealizado.

Tal situação diz respeito ao despreparo do meio urbano de destino para receber os migrantes. A falta de segurança social, emprego e solidariedade, aliada a um excesso de ameaças provenientes deste meio são notórios conspiradores contra o equilíbrio psicossomático dessas pessoas. Ao mesmo tempo, a perspectiva de saúde encontrada nos Centros de Saúde adota uma postura essencialmente "biologicista", com pouca abertura para entender os problemas psicossociais e, com isso, tratar de doenças psicossomáticas.

\section{Referências}

André, M.E.D.A. (1983). Texto, contexto e significados: algumas questões na análise de dados qualitativos. Cadernos de Pesquisa (São Paulo), 45, 66-71.

Blauner, B. (1987). Problems of editing "first person" Sociology. Qualitative Sociology, 10(1), 46-64.

Bogdan, R.C. \& Biklen, S.K. (1998a). Qualitative research methods for education. Thousand Oaks: Sage.

Bogdan, R.C. \& Biklen, S.K. (1998b). Qualitative research for education: an introduction for theory and methods ( $3^{\text {rd }}$ ed.). Boston: Allyn and Bacon.

Boltanski, L. (1979). As classes sociais e o corpo. Rio de Janeiro: Graal.

Caldeira, T.P.R. (1984). A política dos outros: cotidiano dos moradores da periferia e o que pensam do poder e dos poderosos. São Paulo: Brasiliense.

Corin, E.E. (1990). Facts and meaning in psychiatry: An anthropological approach to the lifeworld of schizophrenics. Cultural Medicine and Psychiatry, 14(2), 153-188.

Dejours, C. (1992). A Loucura do Trabalho: estudo de psicopatologia do trabalho. São Paulo: Cortez-Oboré.

Durham, E.R. (1978). A caminho da cidade: a vida rural e a migração para São Paulo. São Paulo: Perspectiva.

Fabrega, H. Jr. (1989). On the significance of an anthropological approach to schizophrenia. Psychiatry, 52(1), 45-55.

Fowler, F. (1993). Survey research methods. Thousand Oaks, CA: Sage.

Gold, S.J. (1992). Mental health and illness in Vietnamese refugees. Western Journal of Medicine, 157(3), 290-294.

Grypma, S. (1993). Culture Shock. Canadian Nurse, 89(8), 33-36.

Habermas, J. (1985). Intermediate reflections: system and lifeworld. In: Habernas, J. (Ed.) Lifeworld and system: a critique of funcionalist reason ( $3^{\text {rd }}$ ed. - corrected, pp. ). Beacon Press.

Jakobson, R. (1969). Lingüística e Comunicação. São Paulo: Cultrix.

Jaspers, K. (1979). Psicopatologia Geral (2 ${ }^{\mathrm{a}}$ ed.). Rio de Janeiro: Atheneu.

Kvale, S. (1996). Interviews: an introduction to qualitative research interviewing. USA: Sage.

Levi-Strauss, C. (1996). Antropologia Estrutural (Cap. 10, Vol. 7, Série Biblioteca Tempo Universitário). Rio de Janeiro: Tempo Brasileiro. 
Ludke, M. \& André, M.E.D.A. (1986). Pesquisa em educação: abordagens qualitativas. São Paulo: EPUT.

Martins, J. \& Bicudo, M.A.V. (1989). A pesquisa qualitativa em psicologia: fundamentos e recursos básicos ( $1^{\mathrm{a}}$ ed.). São Paulo: Moares/Educ.

Moore, W.E. (1968). O impacto da indústria - modernização de sociedades tradicionais. Rio de Janeiro: Jorge Zahar.

Morse, J.M. (1994). Designing funded qualitative research. In: Denzin, N.K. \& Lincoln, Y.S. (Eds.) Handbook of Qualitative Research. London: Sage.

Moscovici, S. (2003). Representações Sociais: Investigações em Psicologia Social (Coleção Psicologia Social). Petrópolis: Vozes.

Ory, F.G. (1991). Children who cross cultures. Sociological Scientific Medicine 32(1), 29-34.

Pope, C. \& Mays, N. (1995). Qualitative research: reaching the parts other methods cannot reach: an introduction to qualitative methods in health and health services research. British Medical Journal, 311(6996), 42-45.

Queiroz, M.S.(1991).Representações sobre Saúde e Doença: agentes de cura e pacientes no contexto do SUS. Campinas: UNICAMP

Quintero, L.F.J. (1989). Enfermedad y medico. Transculturación en el descubrimiento de America/Disease and the physician. Transculturation in the discovery of the New World. Actas Luso Españolas de Neurologia Psiquiatrica y Ciencias Afines, 17(1), 3-14.

Schonauer, K. (1994). Conclusion: Pharmacomarfism of the doctorpatient relationship and liturgy of the physic. In: Schonauer, K. (Ed.) Semiotic Foundations of Drug Therapy: the placebo problem in a new perspective. Berlin, New York, Germany: Mouton de Gruyter.

Smith, L.S. (1996). New russian immigrants: health problems, practices and values. Journal of Cultural Diversity, (3), 68-73.

Sullivan, S.N. (1993). The patient behind the veil: medical culture shock in Saudi Arabia, Comment. Canadian Medical Association Journal, 149(7), 930-931.
Volich, R.M. (2000). Psicossomática: de Hipócrates à Psicanálise (Coleção Clínica Psicanalítica). São Paulo: Casa do Psicólogo.

Zaluar, A. (1994). A máquina e a revolta: as organizações populares e o significado da pobreza ( $2^{\mathrm{a}}$ ed.). São Paulo: Brasiliense.

Miguel Antônio de Mello Silva é Psicólogo, Doutor pela Faculdade de Ciências Médicas - UNICAMP. Professor das Faculdades Integradas do IPEP/Campinas. Endereço para correspondência: Av. Santa Genebra, 287, Jd. Santa Genebra Campinas, SP 13080280.

psicomig@terra.com.br

Marcos de Souza Queiroz é Antropólogo, Doutor pela Universidade de Manchester, Inglaterra, pesquisador titular do Centro de Memória da UNICAMP.

msq44@uol.com.br

Trabalho baseado na tese "Migração e Adoecimento: a cultura e o espaço de simbolização da doença", do Prof. Dr. Miguel Silva e orientação do Prof. Dr. Marcos Queiroz, no programa de doutoramento da Faculdade de Ciências Médicas da Universidade Estadual de Campinas UNICAMP.

\section{Somatização em migrantes de baixa renda no Brasil}

Miguel Antônio de Mello Silva e Marcos de Souza Queiroz Recebido: 03/10/2005

$1^{\mathrm{a}}$ revisão: $13 / 12 / 2005$

$2^{\mathrm{a}}$ revisão: 23/03/2006

Aceite final: 29/03/2006 